\title{
Effect of low-temperature treatments on photoluminescence enhancement of ion-beam synthesized Si nanocrystals in $\mathrm{SiO}_{2}$ matrix
}

\author{
I. Khatsevich, V. Melnik, V. Popov, B. Romanyuk, V. Fedulov \\ $V$. Lashkaryov Institute of Semiconductor Physics, NAS of Ukraine \\ 41, prospect Nauky, 03028 Kyiv, Ukraine \\ E-mail: romb@isp.kiev.ua; phone/fax: +38(044)-525-57-24
}

\begin{abstract}
The results of experimental researches of photoluminescence (PL) spectra in $\mathrm{Si}$ nanocluster structures obtained by implantation of silicon ions to $\mathrm{SiO}_{2}-\mathrm{Si}$ structures with high-temperature $\left(1100{ }^{\circ} \mathrm{C}\right)$ and following low-temperature annealings in various regimes are given. We have found that additional low-temperature treatments in definite regimes result in substantial increase of the PL intensity, thus a maximum effect is observed after annealing in air. The possible mechanisms of the obtained effects are discussed. Those are based on supposition about the dominating contribution of luminescence through the electronic states on $\mathrm{SiO}_{2}-\mathrm{Si}$ nanoclaster interfaces, which is related to defect and impurity complexes. It has been shown that growth of the PL intensity is governed by two effects: generation of new centers of radiative recombination on the nanocrystal-dielectric matrix interfaces, and passivation of nonradiative recombination centers.
\end{abstract}

Keywords: photoluminescence, ion implantation, annealing, nanocluster.

Manuscript received 23.09.08; accepted for publication 20.10.08; published online 11.11.08.

\section{Introduction}

Luminescent properties of silicon nanoclusters built in dielectric matrices $\left(\mathrm{SiO}_{2}, \mathrm{Si}_{3} \mathrm{~N}_{4}\right.$, silicon oxynitride) are investigated in recent years through perspectives of application of these structures in opto- and microelectronics [1-3]. Standard procedures for fabrication of experimental samples are: ion implantation of silicon in $\mathrm{SiO}_{2}$ layer [3, 4]; deposition of $\mathrm{SiO}_{x}$ or silicon oxynitride layers by different methods with a following hightemperature $\left(1000\right.$ to $\left.1150{ }^{\circ} \mathrm{C}\right)$ thermal annealing $[5,6]$. To improve luminescent properties of the obtained structures, the additional impurity doping (nitrogen, carbon, rare-earth elements) $[3,7,8]$, passivation of $\mathrm{P}_{\mathrm{b}^{-}}$ centers by hydrogen $[9,10]$, or additional lowtemperature treatments $[11,12]$ are used. It is also shown that the annealing atmosphere affects on intensity and position of a luminescence band [13-15].

When explaining the physical mechanisms of additional low-temperature treatments and/or atmosphere influence, most of the authors use the models of luminescence via charge carrier recombination in a nanocluster (quantum model) $[4,5,10]$, or through the electronic states at the $\mathrm{Si}$ nanocluster-dielectric matrix interfaces $[2,6,9]$.
In [11], to explain the effect of PL intensity increase at low-temperature annealing, the model of thermodonor center generation at the nanoclusterdielectric matrix interface was proposed, which could be taken into account for the PL bands within the range of 1.5 to $1.75 \mathrm{eV}$. However, up to now there is no common model of interface or thermodonor centers, and also explanation of the low-temperature treatment influence on the intensity and position of the luminescence band.

In this work, we try to discriminate the mechanisms of additional low-temperature treatment influence on PL of the $\mathrm{Si}$ nanocluster structures created by ion implantation of silicon into a $\mathrm{SiO}_{2}$ matrix: passivation of the non-radiative recombination centers or generation of additional centers for radiative recombination. The use of wide set of annealing ambient (nitrogen, argon, hydrogen, mixture of oxygen and nitrogen) and annealing regimes is the feature of our experiments.

\section{Experimental}

p-Si (100) $(10 \mathrm{Ohm} \cdot \mathrm{cm})$ wafers were oxidized in the atmosphere of wet oxygen to the $\mathrm{SiO}_{2}$ thickness of $350 \mathrm{~nm} . \mathrm{Si}^{+}$ion implantation in $\mathrm{SiO}_{2}$ with the energy $E=$ $100 \mathrm{keV}$ and dose interval of $2 \times 10^{16}$ to $1.2 \times 10^{17} \mathrm{~cm}^{-2}$ 
was performed. For formation of the silicon nanoclusters all the samples were annealed at the temperature of $1100{ }^{\circ} \mathrm{C}$ during $20 \mathrm{~min}$ in atmosphere of inert gas (Ar) or nitrogen. Then structures with formed silicon nanoclusters were exposed to low-temperature treatments at the temperatures within the interval of 400 to $850{ }^{\circ} \mathrm{C}$ in various ambients (vacuum, nitrogen, hydrogen, oxygen, and mixtures of those).

PL spectra were measured at room temperature and excitation by the continuous-mode solid-state laser $(473 \mathrm{~nm})$.

\section{Results}

PL spectra of the $\mathrm{SiO}_{2} / \mathrm{Si}$ samples implanted by different doses of $\mathrm{Si}$ ions after high-temperature forming are shown in Fig. 1.

At the small dose of implanted silicon $\left(2 \times 10^{16} \mathrm{~cm}^{-2}\right)$, after the high-temperature annealing in Ar the PL bands are not observed. Weak PL band near the wavelength $\lambda=700 \mathrm{~nm}$ is observed after annealing in nitrogen. At higher $\mathrm{Si}^{+}$doses PL is observed in a longwave region. With increasing implanted silicon dose, the PL band shifts to the longwave side, and the PL intensity decreases. In the samples annealed in $\mathrm{N}_{2}$ ambient, the PL intensity is higher, and the band position is displaced to the shortwave range, as compared with the similar samples formed in Ar. In addition, in the PL spectrum of the samples formed in nitrogen, there exists a weak PL band at the shortwave region $(\sim 560 \mathrm{~nm})$ that is not observed after formation in an inert atmosphere.

The maximum photoluminescence intensity was observed for the samples with the dose of $\mathrm{Si}$ implantation of $9.5 \times 10^{16} \mathrm{~cm}^{-2}$ in all the annealing regimes. So, the given below results concerning the influence of the additional low-temperature annealing on the PL intensity are related to the samples with this implantation dose and forming annealing at $1100{ }^{\circ} \mathrm{C}$, 20 min, Ar or $\mathrm{N}_{2}$ ambient.

Photoluminescence spectra of the samples after combined annealing (forming high-temperature one, and subsequent low-temperature at $450{ }^{\circ} \mathrm{C}$ in air) are shown in Fig. 2.

The PL intensity after low-temperature annealing is substantially higher (by 10 times for the samples formed in Ar, and by 4 times - in $\mathrm{N}_{2}$ ), and PL peak is shifted a little to the longwave side (PL maximum is close to $790 \mathrm{~nm}$ ). In the shortwave region, after the lowtemperature annealing the new PL band with its peak at $590 \mathrm{~nm}$ appears for all the samples. The intensity of this band increases with the implanted silicon dose.

PL spectra of the samples after annealing in hydrogen $\left(480{ }^{\circ} \mathrm{C}, 2 \mathrm{~h}\right)$ are shown in Fig. 3. Annealing in hydrogen leads to PL growth both after a forming annealing, and after a low-temperature annealing in air.

The most intensive luminescence is observed for the samples formed in Ar, the annealed at low temperature in air, and then annealed in hydrogen.

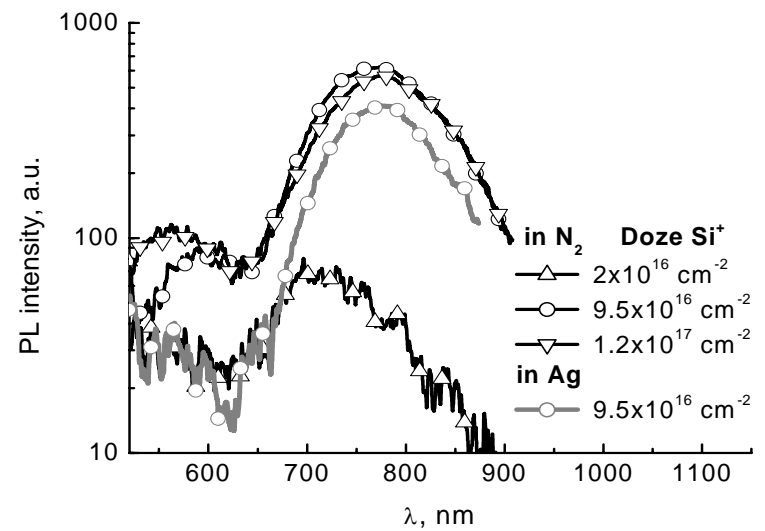

Fig. 1. PL spectra of the $\mathrm{SiO}_{2} / \mathrm{Si}$ samples implanted with $\mathrm{Si}$ at different doses, after the high-temperature forming annealing $\left(1100{ }^{\circ} \mathrm{C}, 20 \mathrm{~min}, \mathrm{Ar}\right.$ or $\left.\mathrm{N}_{2}\right)$.

Additional temperature treatment within the range of 500 to $800{ }^{\circ} \mathrm{C}$ did not result in substantial increase of PL.

The PL integral intensity after the different stages of the structure annealing is given in Table.

\section{Discussion}

As it was shown in the set of papers $[2,4,9,16]$, in the $\mathrm{SiO}_{2}-\mathrm{Si}$ structures implanted by silicon, during the following high-temperature annealing, Si nanoclusters with sizes of 1 to $6 \mathrm{~nm}$ are formed (depending on the implantation dose and annealing time). With the implantation dose increase, the nanocluster concentration increases, and it leads to growth of the PL intensity (regardless of the mechanism of radiative recombination of non-equilibrium charge carriers). Growth of the large clusters goes at the expense of decay of the small ones. It results in reduction of the cluster concentration, the total area of the $\mathrm{SiO}_{2}-\mathrm{Si}$ boundaries diminishes too, which leads to reduction of the PL intensity both in the case of radiative recombination in the nanoclusters, and recombination via the interface states (Fig. 1).

The PL intensity in the samples formed in nitrogen (in comparison with Ar) ambient is higher due to passivation of dangling bonds (that are non-radiative recombination centers) by nitrogen, and also owing to formation of additional energy states (that act as radiative recombination centers) at $\mathrm{SiO}_{2}-\mathrm{Si}$ interfaces.

Table. PL integral intensity values (arb. un.) after the stages of structure formation.

\begin{tabular}{|c|c|c|c|c|}
\hline \multicolumn{2}{|c|}{ Forming } & \multicolumn{3}{c|}{$\begin{array}{c}\text { Low-temperature annealing } \\
\text { conditions }\end{array}$} \\
\hline $\begin{array}{l}\text { Atmo- } \\
\text { sphere }\end{array}$ & $1100{ }^{\circ} \mathrm{C}$ & $\begin{array}{c}450{ }^{\circ} \mathrm{C} \\
\text { (air) }\end{array}$ & $\begin{array}{c}480{ }^{\circ} \mathrm{C} \\
\left(\mathrm{H}_{2}\right)\end{array}$ & $\begin{array}{c}450{ }^{\circ} \mathrm{C} \text { (air) }+ \\
480{ }^{\circ} \mathrm{C}\left(\mathrm{H}_{2}\right)\end{array}$ \\
\hline $\mathrm{Ar}$ & 58 & 523 & 400 & 976 \\
\hline $\mathrm{N}_{2}$ & 103 & 382 & 500 & 509 \\
\hline
\end{tabular}




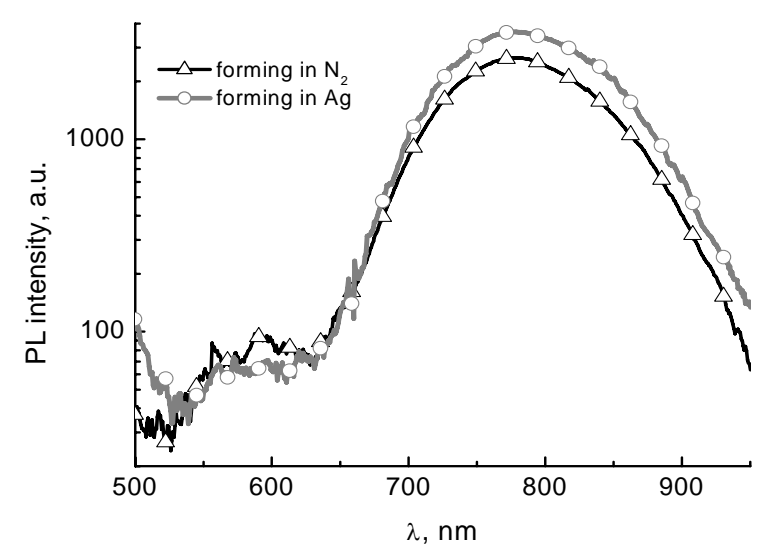

Fig. 2. PL spectra of the samples after the additional lowtemperature annealing $\left(450^{\circ} \mathrm{C}, 2 \mathrm{~h}\right.$, air $)$.

The PL band with its peak at $560 \mathrm{~nm}$, as a rule, is attributed to the defects in the $\mathrm{SiO}_{2}$ phase, and it disappears after a high-temperature annealing. Presence of this band in the samples annealed in nitrogen is the evidence of nitrogen interaction with defects, which increases their thermostability.

An additional annealing of the samples at the temperature $450{ }^{\circ} \mathrm{C}$ in vacuum or argon environment does not cause noticeable changes in PL spectra. The substantial changes of spectra are observed after the lowtemperature annealing in the environments of reactive gases (hydrogen, nitrogen, oxygen) and their mixtures. The most intensive PL is observed in the samples formed at $1100{ }^{\circ} \mathrm{C}$ in argon, and then subjected to the additional heat treatment in air at $450{ }^{\circ} \mathrm{C}$ and the following annealing in hydrogen at the temperature $480{ }^{\circ} \mathrm{C}$.

To explain the obtained results, we propose the model of processes that take place at the combined annealing of the $\mathrm{SiO}_{2}-\mathrm{Si}$ structures implanted by silicon. When annealing in argon, Si clusters are formed, and numerous dangling bonds at the nanocluster- $\mathrm{SiO}_{2}$ interfaces are created; the low intensity of PL (comparatively with the structures annealed in nitrogen, where part of the bonds is passivated) confirms this.

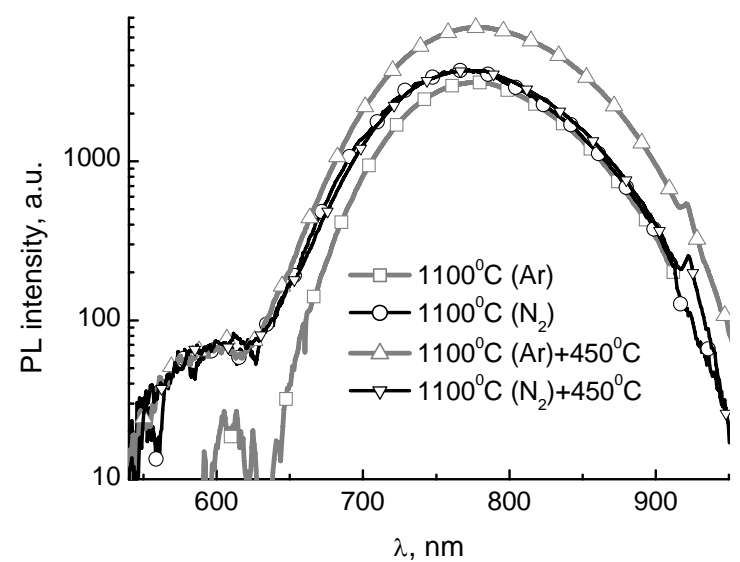

Fig. 3. PL spectra of the samples after the additional annealing in hydrogen $\left(480^{\circ} \mathrm{C}, 2 \mathrm{~h}\right)$.
Confirmation of this is that the additional annealing in $\mathrm{H}_{2}$ of the samples, formed in Ar, results in PL intensity growth by $\sim 7$ times, while for the samples formed in nitrogen the PL intensity grows by 5 times only. At the low-temperature annealing of the samples in air, the quasichemical reactions take place at nanocluster-matrix boundaries with participation of oxygen, nitrogen and silicon. It results in the interface energy states formation, through which the processes of radiative recombination occur. In the earlier works devoted to investigations of $\mathrm{SiO}_{2}-\mathrm{Si}$ interface, it was shown that annealing at the temperature $450{ }^{\circ} \mathrm{C}$ results in the sharp increase of the density of electronic states at this interface [17].

More effective formation of radiative centers takes place when there is a large concentration of dangling bonds (high-temperature annealing in argon) in structures. In the case of the forming annealing in nitrogen ambient, the concentration of these bonds is less, as a result, the rate of new center formation is less. The process of electronic state formation at lowtemperature annealing goes until a shell of defect complexes (containing nitrogen, oxygen and silicon) will be formed around the silicon nanocrystal. The presence of dangling bonds before the low-temperature annealing promotes activation of the autocatalytic for the process mechanism of radiative center formation [17].

At the same time, formation of radiative centers at $\mathrm{SiO}_{2}-\mathrm{Si}$ interfaces is accompanied with creation of new dangling bonds that are the centers of non-radiative recombination. It follows from the results on a subsequent annealing in hydrogen, when dangling bonds are passivated, and the PL intensity increases, Table. The much larger growth of the PL intensity is observed after the treatment in $\mathrm{H}_{2}$ ambient in the samples formed in argon with the additional low-temperature treatment (air) in comparison with the samples formed in nitrogen. It is the evidence that in the samples formed in $\mathrm{N}_{2}$, at the low-temperature annealing in air, lower concentrations of complexes with radiative characteristics and dangling bonds are formed, as the $\mathrm{Si}$ nanocluster- $\mathrm{SiO}_{2}$ interfaces are strongly passivated when formation goes in $\mathrm{N}_{2}$ ambient.

\section{Conclusions}

The results of experimental researches of photoluminescence spectra of the $\mathrm{Si}$ nanocluster structures obtained by implantation of silicon ions to $\mathrm{SiO}_{2}-\mathrm{Si}$ structures and high temperature $\left(1100^{\circ} \mathrm{C}\right)$ and following low-temperature annealings in different environments are given. It is shown that the PL intensity grows within the range of implantation doses $2 \times 10^{16}-9 \times 10^{16} \mathrm{~cm}^{-2}$. At subsequent increase of the dose, there is reduction of the PL intensity and shift of the PL band peak to the longwave side.

The additional low-temperature treatments result in the substantial increase in the PL intensity, thus a maximum effect is observed after annealing in air. The spectral position of the PL band changes weakly. 
Comparison of effect of passivation of nonradiative recombination centers due to the lowtemperature annealing in the nitrogen or hydrogen atmosphere has been carried out. It has been shown that growth of the PL intensity is caused by these two effects: generation of new centers providing radiative recombination at the nanocrystal-dielectric matrix interfaces, and passivation of non-radiative recombination centers. Generation of the new centers of radiative recombination at low-temperature treatments in air goes more effectively in the samples formed at the high temperature annealing in argon ambient, comparatively with annealing in nitrogen.

\section{Acknowledgements}

This work was supported by the MES of Ukraine (Grant \# M/175-2007).

\section{References}

1. L. Pavesi, L. Dal Negro, C. Mazzoleni, G. Franzo and F. Priolo, Optical gain in silicon nanocrystals // Nature 408, p. 440-444 (2000).

2. G.G. Ross et al., Effect of implanted Si concentration on the Si nanocrystal size and emitted PL spectrum // Nuclear Instruments and Methods in Physics Research B 256, p. 211-215 (2007).

3. B.M. Romanyuk et al., Photoluminescense of nanoclusters in $\mathrm{SiO}_{2}$ layers implanted with silicon and carbon ions // Optoelektronika i poluprovodnikovaya tekhnika 42, p. 96-102 (2007) (in Russian).

4. U.S. Sias, M. Beha, H. Boudinov, E.C. Moreira, Influence of the implantation and annealing parameters on the photoluminescence produced by $\mathrm{Si}$ hot implantation // Nuclear Instruments and Methods in Physics Research B 257, p. 51-55 (2007).

5. N. Daldosso et al., Silicon nanocrystal formation in annealed silicon-rich silicon oxide films // J. Appl. Phys. 101, 113510 (1-7) (2007).

6. L. Dal Negro et al., Light-emitting silicon-rich nitride system and photonic structures // J. Experim. Nanoscience 1(1), p. 29-50 (2006).
7. J. Zhao et al., Short-wavelength photoluminescence from silicon and nitrogen coimplanted $\mathrm{SiO}_{2}$ films // Appl. Phys. Lett. 74 (10), p. 1403-1405 (1999).

8. D. Pacifici et al., Erbium-doped Si nanocrystals: optical properties and electroluminescent devices // Physica E 16, p. 331-340 (2003).

9. B. Garrido Fernandez et al., Influence of average size and interface passivation on the spectral emission of Si nanocrystals embedded in $\mathrm{SiO}_{2} / / \mathrm{J}$. Appl. Phys. 91(2), p. 798-807 (2002).

10. S. Cheylan and R.G. Elliman, Effect of particle size on the photoluminescence from hydrogen passivated $\mathrm{Si}$ nanocrystals in $\mathrm{SiO}_{2} / /$ Appl. Phys. Lett. 78(13), p. 1912-1914 (2001).

11. Xiaochun $\mathrm{Wu}$ et al., Kinetic oscillations of red photoluminescence from nanocrystalline $\mathrm{Si} / \mathrm{SiO}_{2}$ films // Appl. Phys. Lett. 77(5), p. 645-647 (2000).

12. M. Lopez et al., Elucidation of the surface passivation role on the photoluminescence emission yield of silicon nanocrystals embedded in $\mathrm{SiO}_{2}$ // Appl. Phys. Lett. 80(9), p. 1637-1639 (2002).

13. A.R. Wilkinson and R.G. Elliman, The effect of annealing environment on the luminescence of silicon nanocrystals in silica // J. Appl. Phys. 96(7), p. 4018-4020 (2004).

14. U.S. Sias et al., The post-annealing environment effect on the photoluminescence recovery of ionirradiated Si nanocrystals // Nuclear Instruments and Methods in Physics Research B 257, p. 6-10 (2007).

15. X.X. Wang et al., Origin and evolution of photoluminescence from Si nanocrystals embedded in a $\mathrm{SiO}_{2}$ matrix // Phys. Rev. B 72, 195313 (1-6) (2005).

16. G. Nicotra, G. Franzo, C. Spinella, Evaluation of the excess and clustered silicon profiles in a silicon implanted $\mathrm{SiO}_{2}$ layer // Nuclear Instruments and Methods in Physics Research B 257, p. 104-107 (2007).

17. V.G. Litovchenko, A.P. Gorban, Bases of Physics of the Metal-Insulator-Semiconductor Microelectronic Systems. Naukova Dumka Publ., Kiev, 1978, p. 316 (in Russian). 